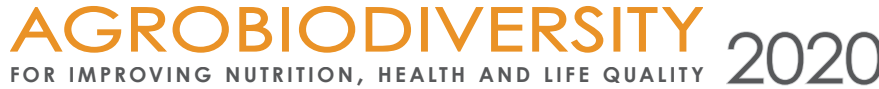

e

\section{POSSIBILITY OF USING AN INVASIVE SPECIES ADENOCAULON ADHAERESCENS MAXIM. (ASTERACEAE) AS A MEDICIN PLANT}

\author{
Vinogradova Yulia $^{1 *}$, Shelepova Olga ${ }^{1}$, Vergun Olena $^{2}$, Ganina Anastasia $^{1}$ \\ ${ }^{1}$ N.V. Tsitsin Main Botanical Garden, Russian Academy of Sciences, Moscow, Russia \\ ${ }^{2}$ M.M. Gryshko National Botanical Garden of the NAS of Ukraine, Kyiv, Ukraine
}

Received: 18. 5. 2020 Revised: 12. 7.2020 Published: 20. 11.2020

\begin{abstract}
Many alien invasive species are characterized by the accumulation of biologically active substances antioxidants, which are used in the prevention of diseases of the cardiovascular system and many cancers. The purpose of this study was to compare the antioxidant (antiradical) properties of Adenocaulon adhaerescens Maxim extracts obtained from plants growing in both natural and secondary distribution ranges. The literature data on the analysis of medicinal properties of closely related species of the genus Adenocaulon are summarized. The antioxidant activity was determined by the method using 2.2-diphenyl-1-picrylhydrazil (DPPH) on spectrophotometer Genesis 20, the USA at the Slovak University of Agriculture in Nitra (Slovak Republic). Water and alcohol extracts (methanol and ethanol) were tested. The total antioxidant activity of extracts from leaves of juvenile plants was about $80 \%$ (alcoholic extracts) and 34\% (water extracts). The total antioxidant activity of leaf extracts collected from flowering plants was 76\% (methanol extracts), 59\% (ethanol extracts), and 48\% (water extracts). The total antioxidant activity of extracts from inflorescences was significantly higher and amounted to 83\% (methanol extracts), 85\% (ethanol extracts), and 49\% (water extracts). Indicators of antioxidant activity of the aboveground part of plants collected in populations from the natural and secondary ranges do not have reliable differences. Methanol extracts from plants collected in the natural range have the antioxidant activity of $77-78 \%$, ethanol extracts of $78-81 \%$, and water extracts of $61-66 \%$. In plants from invasive populations, the antioxidant activity of methanol extracts is $77-80 \%$, ethanol extracts $76-79 \%$, water extracts $32-67 \%$. The studied species demonstrated a significant antioxidant activity comparable to many valuable medicinal plants, such as Urtica dioica L., Bidens pilosa Linn., Acacia auriculiformis A. Cunn, Salvia officinalis L., and others. Thus, alien (A. adhaerescens) which has successfully adapted to the Moscow climate and formed a stable invasive population, may become a potential source of antioxidants to improve the system of antioxidant protection of humans.
\end{abstract}

Keywords: Adenocaulon adhaerescens, antioxidant activity, invasion, alien species

*Corresponding author: Yulia Vinogradova, N.V. Tsitsin Main Botanical Garden, Russian Academy of Sciences, Botanicheskaya, 4, 127276 Moscow, Russia gbsad@mail.ru 


\section{Введение}

Изучение растений в поисках новых лекарственных веществ является одним из основных прикладных направлений ботаники. Многие соединения, выделенные из растений в последнее время в научных лабораториях, исследуются как химиотерапевтические «кандидаты» (Lee, 2010). C каждым годом, тенденция использования растительного сырья увеличивается, и в связи с повышением спроса на натуральные лекарства во многих странах широко культивируют дикорастущие лекарственные растения. Однако до сих пор только 5\% мировой флоры введено в культуру с лекарственными целями, и практически не используется большая группа видов - инвазионные растения, численность которых, а также площадь вторичного ареала во всех регионах мира увеличиваются с каждым годом.

В центре внимания многочисленных исследовательских программ находится разработка противоопухолевых препаратов (Balunas, 2005). Более 60\% противоопухолевых лекарственных средств, используемых в настоящее время, получены из природных источников, включая растения (Cragg, 2005). Чужеродные инвазионные виды растений также могут применяться для лечения опухолей, поскольку содержат вещества с высокой антиоксидантной активностью. В этом отношении наше внимание привлек малоизученный вид Adenocaulon adhaerescens Maxim. Согласно последней ревизии (Bittmann, 1990), Adenocaulon - это небольшой род цветковых растений семейства Астровые, впервые описанный Вильямом Гукером (Hooker, 1829), включающий в себя пять видов и один подвид:

- A. bicolor Hook. - Соединённые штаты, Канада (Nash et al., 1976).

- A. chilense Less. - Чили, Аргентина (Marticorena and Quezada, 1985).

- A. lyratum S.F. Blake - Гватемала (Nash et al., 1976), Чьяпас (Breedlove, 1986).

- A. nepalense Bittmann - Непал (Bittmann, 1986a).

- A. himalaicum Edgew. - Китай, Индия, Япония, Корея, Непал (Yousheng and Hind, 1829).

При этом группа популяций, занимающая северо-восточную часть ареала A. himalaicum auct., чаще рассматривается как отдельный вид $A$. adhaerescens Maxim. Он впервые описан Карлом Максимовичем в его работе по флоре Амура (Maximowicz, 1859).

A. adhaerescens (прилипало пристающее) - многолетнее травянистое растение (Рисунок 1). Побеги прямостоячие с очередным листорасположением, высота растений второго года жизни - до 80 см. Листья простые, черешковые. Нижняя поверхность листа покрыта густым войлочным опушением. Цветение - июнь-октябрь. Плоды - семянки зелёного цвета, с железистыми трихомами (Fahn, 1988; Vinogradova, 2013). В 1953 году A. adhaerescens интродуцирован в Главный ботанический сад Академии Наук СССР (Москва). Через 30 лет отдельные особи были отмечены за пределами экспозиции. В настоящее время этот вид встречается массово вдоль дорожек по всему ботаническому саду, внедряется в естественные ценозы и формирует крупные (площадью до 5 м) локальные микропопуляции плотностью 50 растений на м². В 2005 г. A. adhaerescens обнаружен в парке Останкино и на ВДНХ, которые граничат с ГБС, а в 2007 г. отмечен 
Vinogradova, Y., Shelepova, O., Vergun, O., Ganina, A.

Agr.bio.div. Impr. Nut., Health Life Qual., 2020, 59-69

в лесопарке возле метро Щукинская. Размножается преимущественно семенным способом (Vinogradova, 2010; Mayorov et al., 2013).

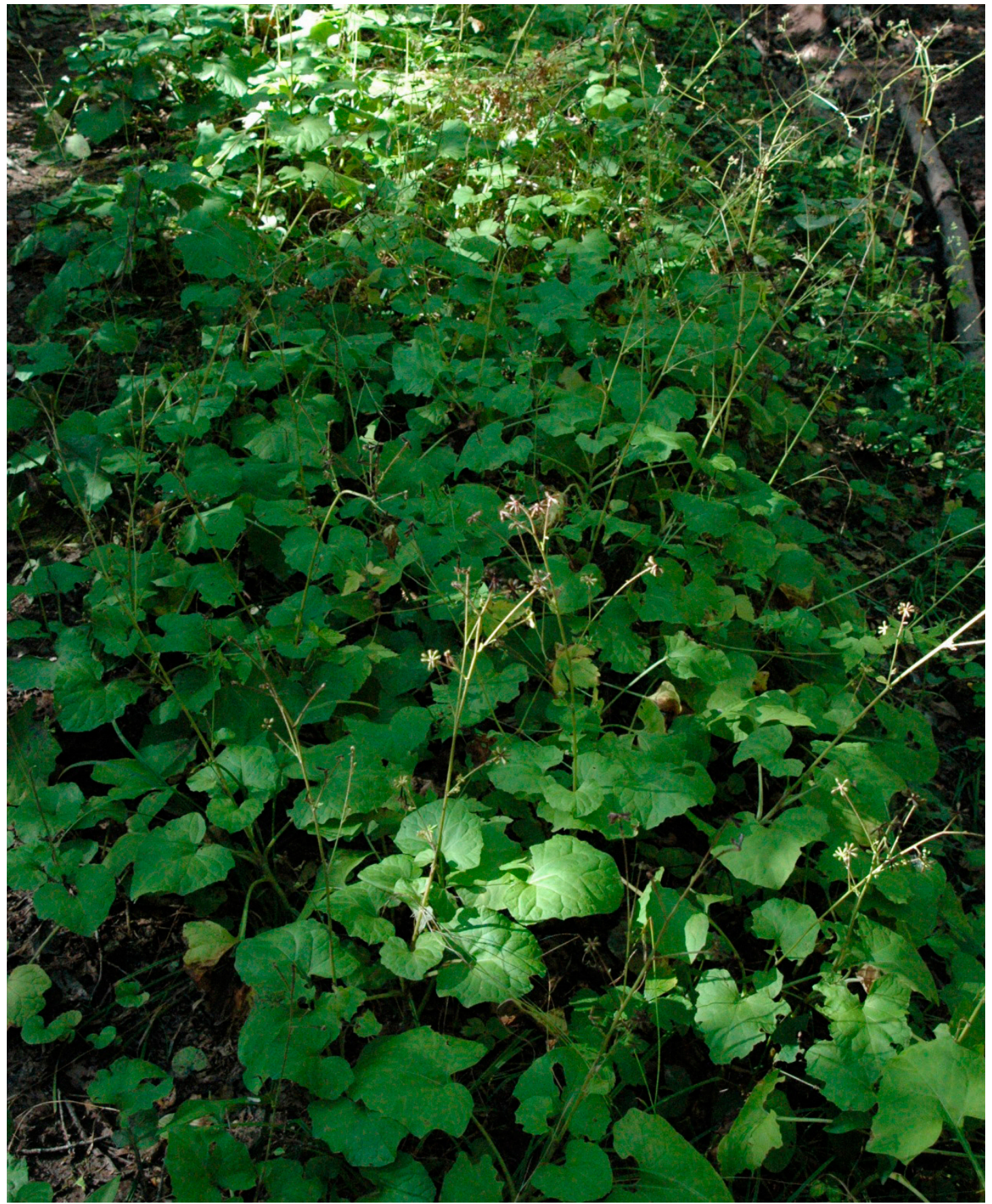

Рисунок 1 Adenocaulon adhaerescens Maxim. в естественном ареале в Приморье

Figure 1 Adenocaulon adhaerescens Maxim. in the native distribution range in the Primorsky Territory 
В качестве источника химических соединений A. adhaerescens paнее не использовался, однако, наземная часть близкородственного вида A. himalaicum Edgew применяется в районах его естественного произрастания - Китае, Корее и Японии для лечения абсцессов, кровоизлияний и воспалений (Hak, Kang, 2001; Wang et al., 2007).

Основными действующими компонентами $A$. himalaicum являются производные кофеиновой кислоты (Kulesh et al., 1986). Химическое исследование метанольного экстракта этого растения привело к выделению двух новых и восьми известных соединений (ацетилен 1-0-ферулоил-тетрадека-4E, 6E, 12E-триен-8,10-диин, монотерпенгликозид 9-гидроксилиноил-3-0-(4-0-кумароил) -j3-D- глюкопиранозид, фитол, парасорбозид, пруназин, (Z)-3-гексенил/3-D-глюкопиранозид и 9-гидроксиналоилглюкозид). С помощью ТН-ЯМР и ГХ-МС анализа были идентифицированы три известныхмоноглицерида, 10-(9Z, 12Z,15Z-октадекатриеноил) глицерин, 1-0-гексадеканоилглицерин и 1-0-(9Z, 12Z-октадекадиеноил) глицерин (Hak, Kang, 2001). Позднее выделен новый трициклический $\alpha, \beta$-ненасыщенный кетон (аденокаулон) и новый $\delta$-гексанолактонгликозид (аденокаулолид) (Wang et al., 2007).

Имеются также данные по скринингу антибактериальной активности A. himalaicum. В качестве контроля использовался хлорамфеникол. Соединение 2 проявляло антибактериальную активность против E. coli и S. aureus, а coединение 4 - против E. coli (Wang et al., 2007).

Экстракты A. himalaicum содержат антипролиферативные соединения, которые протестированы как лекарственные средства. Экстракты оказались активны против аденокарциномы желудка человека (MK-1), рака матки человека (HeLa), меланомы мыши (B16F10) и Т-клеточных человека типа 2 (MT-2), но не активны против лимфотропных вирусов человека типа 1 (HTLV-1) и MT-1 (Kinjo, 2016).

В настоящее время исследуются различные варианты фармакологических вмешательств с целью снижения образования активных форм кислорода и обезвреживания уже имеющихся свободных радикалов с помощью антиоксидантов.

По данным корейских ученых, антиоксидантная активность A. himalaicum низкая: 20,2 \% (метанольные экстракты) и 17,8 \% (водные экстракты) (Lee et al., 2011). Однако уровень антиоксидантной активности экстрактов может меняться под влиянием различных факторов: климат, тип почвы, количество солнечных дней, объем выпавших осадков и т.д. (Goriunova, 2009). К тому же A. adhaerescens, хотя и близок к A. himalaicum, но все же другой вид. Кроме того, он является инвазионным видом, а ранее проведенный нами скрининг других чужеродных инвазионных растений продемонстрировал очень высокую степень выраженности их антиоксидантных свойств (Shelepova et al., 2019; Vinogradova et al., 2019 a,b).

Не менее интересно сравнение естественных и инвазионных популяций одного итого же вида по их биохимическим признакам, в том числе и по антиоксидантной активности. Сравнительный анализ дает возможность прогнозировать успешность 
Vinogradova, Y., Shelepova, O., Vergun, O., Ganina, A.

Agr.bio.div. Impr. Nut., Health Life Qual., 2020, 59-69

и целесообразность искусственного выращивания (культивирования) вида в том случае, если он является потенциально лекарственным растением.

Цель данного исследования - сравнительная оценка антиоксидантных (антирадикальных) свойств экстрактов A. adhaerescens, полученных из растений, произрастающих в условиях как естественного, так и вторичного ареала.

\section{Материалы и методы}

\section{Растительный материал}

Материалом для исследования антиоксидантной активности различных органов растения послужили растения A. adhaerescens из инвазионной популяции, произрастающей в ГБС РАН (Москва, N 55.78 Е 36.80). В апреле 2018 г. собраны листочки ювенильных растений (образец 1), в августе - срединные листья (образец 2) и цветущие побеги (образец 3) растений в генеративной фазе развития (начало цветения).

Материалом для сравнения антиоксидантной активности в популяциях различного географического происхождения являлись пробы всей надземной части растений из 3 популяций естественного ареала и 2 инвазионных популяций вторичного ареала. В сентябре 2019 г. растения собирали в естественном ареале в трех местообитаниях юга Приморского края: E1) остров Русский N 42.97 E 131.89; E2) окрестности г. Уссурийска, буферная зона Уссурийского заповедника N 43.63 E 132.27; E3) г. Владивосток, лесная территория ботанического сада N 43.22 E 131.99. В конце сентября того же года материал собрали в двух инвазионных популяциях вторичного ареала: B1) в лесопарке у метро Щукинская, Москва N 55.80 E 37.47 и B2) в Главном ботаническом саду Российской академии наук.

Материал сушили при комнатной температуре и затем мололи до состояния порошка. Тестировали водные и спиртовые (метанол и этанол) экстракты.

\section{Методика приготовления экстрактов}

Навеску измельченного образца (1 г) экстрагировали в 25 мл растворителя (дистиллированная вода, этанол и метанол). Экстракция проводилась в течение 12 ч при непрерывном перемешивании. После этого экстракты фильтровали для последующего измерения.

\section{ДФПГ-метод определения антирадикальной активности растительных эктрактов}

Антирадикальную активность определяли по методике Brand-Williams et al. (1995) с использованием 2,2-дифенил-1-пикрилгидразила (DPPH) на спектрофотометре Genesis 20 (США). Заранее готовили раствор 2,2-дифенил-1-пикрилгидразила (ДФПГ). Для этого взвешивали 0,025 г радикала, переносили в мерную колбу на 100 мл и доводили до метки метанолом. Данный раствор разбавляли в 10 раз при непосредственном определении плотности исследуемых растворов и хранили 
Vinogradova, Y., Shelepova, O., Vergun, O., Ganina, A.

Agr.bio.div. Impr. Nut., Health Life Qual., 2020, 59-69

в холодильнике. Плотность рабочего раствора радикала находилась в пределах 0,700-0,800. В кювету добавляли 3,9 мл раствора ДФПГ и измеряли плотность на спектрофотометре. Добавляли 100 мл исследуемого раствора и оставляли в темноте на 10 минут. После этого снова проводили измерения полученных экстрактов на спектрофотометре. Полученные результаты рассчитывали в процентах с использованием следующего уравнения: \% Inh $=\left(A_{0}-A_{1}\right) / A_{0} \times 100$, где: $A_{0}$ - поглощение контрольного раствора (раствор радикала); $A_{1}$ - оптическая плотность раствра в присутствии образца.

\section{Статистические методы}

При анализе полученных данных использовали среднее значение и стандартное отклонение трех повторностей. Статистический анализ выполнен в программе PAST 2.17. Данные проанализированы с помощью теста ANOVA, различия между средними значениями признака проверены по критерию множественных сравнений ТьюкиКрамера $(p<0.05)$.

\section{Результаты и их обсуждение}

Группа инвазионных растений, наряду с другими растениями, является потенциальным источником сырья для фармакологических исследований благодаря ряду полезных свойств, которые могут использоваться в медицинских целях (Pappan and Thomas, 2017; Kozuharova et al., 2019). Растения из семейства Астровых представляют научный интерес не только в области ботаники и экологии, а также как источник биологически активных веществ и как сырье с различной биологической активностью, в том числе и антиоксидантной (Bessada et al., 2015). Одним из наиболее известных и широко применяемых методов определения антирадикальной активности растительных экстрактов является реакция обесцвечивания раствора радикала экстрактом исследуемого образца (ДФПГ-метод). Метод отличается простотой, не занимает много времени и относительно экономичен (Marinova and Batchvarov, 2011). Проведенные нами исследования антиоксидантной активности различных органов A. adhaerescens, произрастающего во вторичном ареале в ГБС РАН, показали, что все органы растения обладают антиоксидантной активностью, хотя и в разной степени. Общая антиоксидантная активность экстрактов из листьев ювенильных растений, собранных в апреле, была высокой и составила около 80 \% (метанольные и этанольные экстракты) и 35 \% (водные экстракты). При этом общая антиоксидантная активность экстрактов из листьев, собранных в сентябре с цветущих растений, также оставалась повышенной и составила около 77 \% (метанольные экстракты), 60 \% (этанольные экстракты) и 48 \% (водные экстракты) (Рисунок 2). Но наиболее высокой была общая антиоксидантная активность экстрактов из соцветий, она достигала практически 85 \% для этанольных и метанольных экстрактов и практически 50 \% для водных экстрактов. 


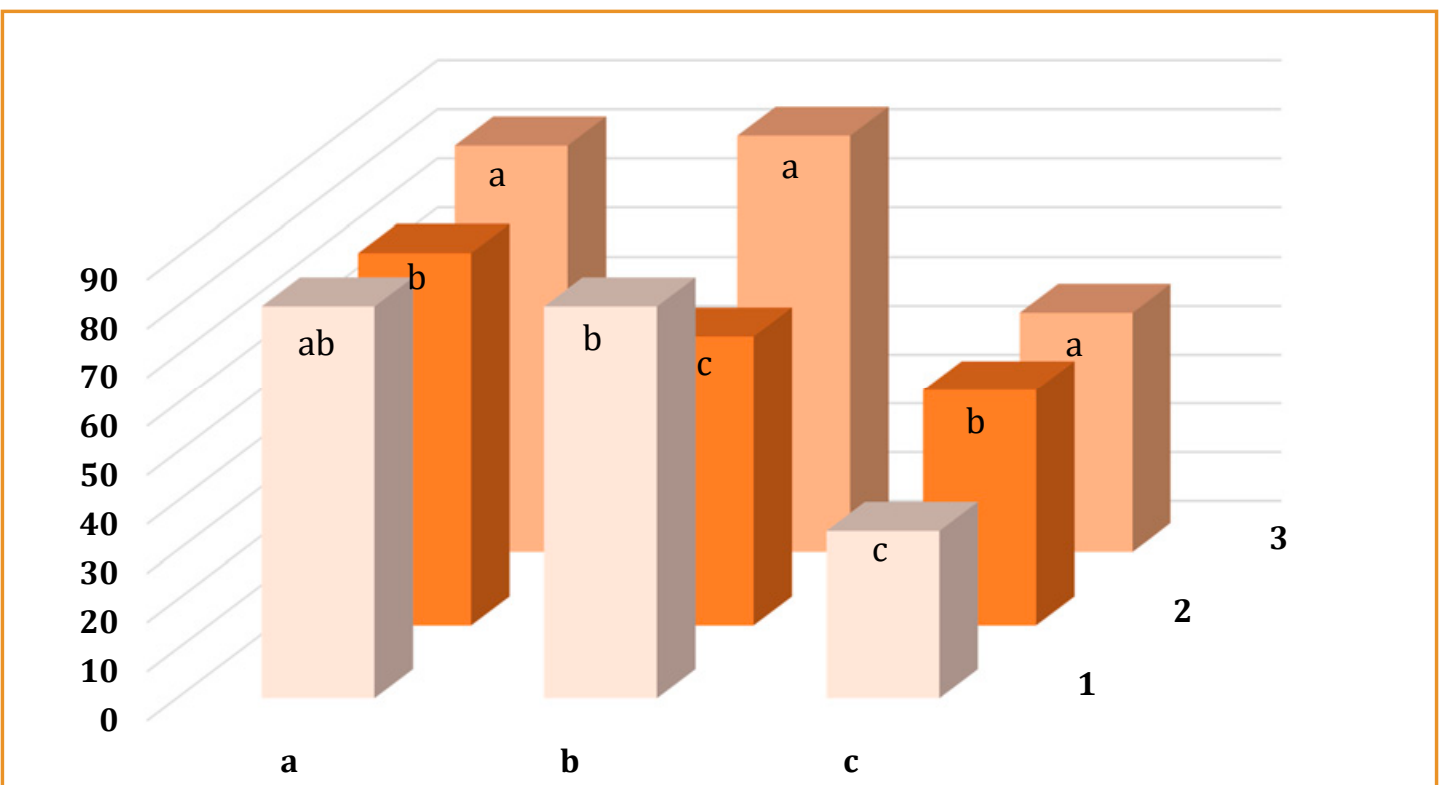

Рисунок 2 Антиоксидантная активность экстрактов из разных органов Adenocaulon adhaerescens Махіт методом ДФПГ (\%)

1 - листья ювенильных растений; 2 - листья генеративных растений; 3 - соцветия; а - метанольные экстракты; b - этанольные экстракты; с - водные экстракты (средние значения признака в колонке, обозначеннойбуквами, существенно не отличаются, $P \leq 0,05$ )

Figure 2 Antioxidant activity of extracts of different organs of Adenocaulon adhaerescens Maxim by DPPH method (\%)

1 - leaves of juvenile plants; 2 - leaves of generative plants; 3 - inflorescences; a - methanol extracts; b ethanol extracts; c - water extracts (means in each column followed by different letters are not significantly different $(P \leq 0.05)$

Однако в практике фармакопеи экономически более целесообразно собирать и использовать не отдельные органы, а всю надземную часть растения. Это тем более относится к изучаемому виду, у которого соцветие обильно олиственно. Поэтому для сравнения антиоксидантной активности растений из естественного и вторичного ареалов мы брали всю надземную часть растений целиком. Результаты исследований представлены на Рисунке 3.

Показатели антиоксидантной активности спиртовых экстрактов листьев и соцветий исследованных растений выше, чем водных. Это говорит, вероятно, о содержании в растения большей частью спирторастворимых антиоксидантов фенольной природы, которые придают данному виду лекарственные свойства.

Существенных различий по показателям антиоксидантной активности растений из естественного и вторичного ареала не выявлено. Метанольные экстракты из растений, собранных в естественном ареале, обладают антиоксидантной активностью 77 - 78 \%, этанольные - 78 - 81 \%, водные - 61 - 66 \%. У растений из инвазионных популяций антиоксидантная активность метанольных экстрактов составляет 77 - $80 \%$, этанольных - 76 - $79 \%$, водных - 32 - $67 \%$. 


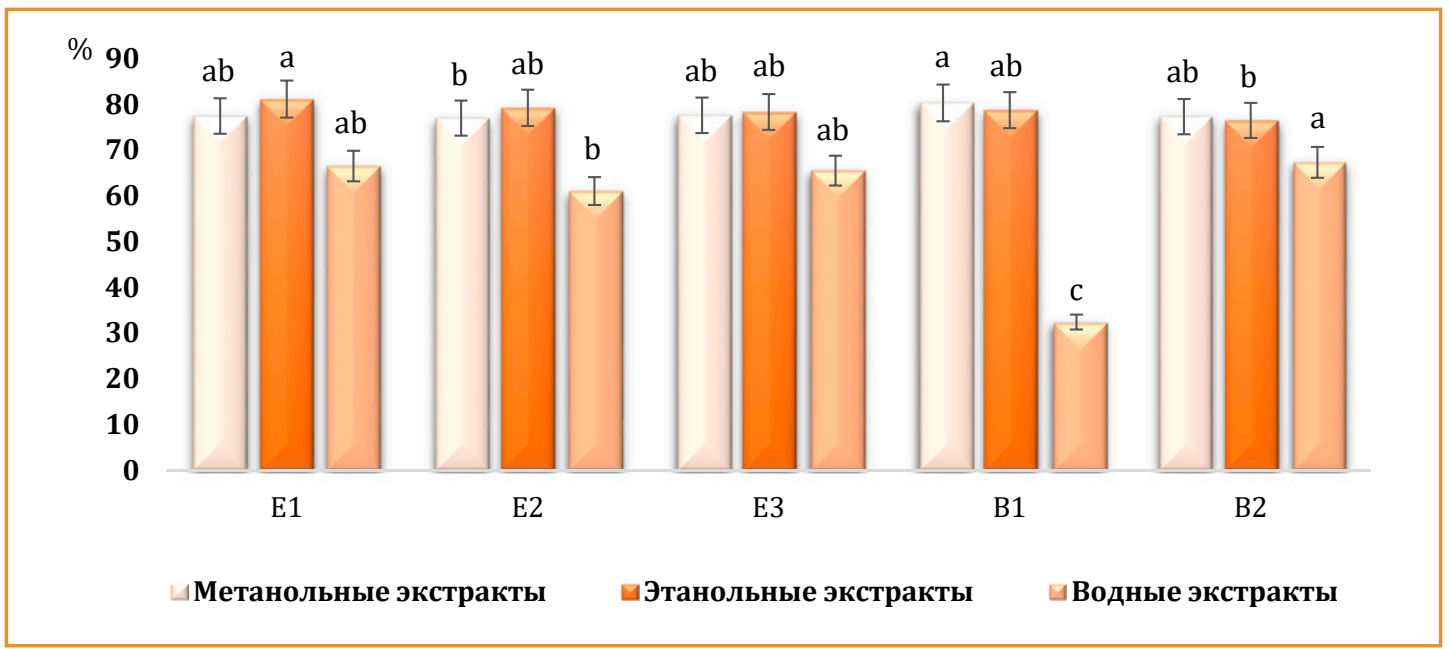

Рисунок 3 Антирадикальная активность A. adhaerescens Maxim в популяциях различного географического происхождения

Е1 - остров Русский; Е2 - Уссурийский заповедник; Е3 - Ботанический сад-институт ДВО РАН; В1 - Щукинский лесопарк; В2 - Главный ботанический сад РАН (средние значения признака в колонке, обозначенной буквами, существенно не отличаются, $p \leq 0,05$ )

Figure 3 Antiradical activity of $A$. adhaerescens Maxim in the populations of different origins

E1 - island Russian; E2 - Ussuri Nature Reserve; E3 - Botanical garden-institute FEB of RAS; B1 - Schukin Forest Park; B2 - Main Botanical Garden of RAS (means in each column followed by different letters are not significantly different $(p \leq 0.05)$

Таким образом, наши результаты демонстрируют значительную вариабельность фитохимических характеристик $A$. adhaerescens в течение вегетационного сезона и очень высокую антиоксидантную активность (свыше 80 \%) спиртовых экстрактов из молодых листьев и соцветий данного вида. Изученный вид продемонстрировал значительную антиоксидантную активность, сопоставимую со многими ценными лекарственными растениями, такими как Urtica dioica L., Bidens pilosa Linn., Acacia auriculiformis A. Cunn, Salvia officinalis L., Polyalthia cerasoides (Roxb.) Bedd. и др. (Krishnaiah et al., 2011). Антиоксидантная активность спиртовых экстрактов из молодых листьев и соцветий A. adhaerescens оказалась на уровне аналогичных показателей, зафиксированных у воздушно-сухих листьев Solidago canadensis L. (84 \%) (Shelepova et al., 2019) и существенно выше, чем у листьев S. virgaurea L. (64 \%) (Demir et al., 2009) и листьев Conyza bonariensis (L.) Cronquist (58 \%) (Daur, 2015). Другое исследование группы растений из семейства Астровых показало, что антиоксидантная активность водных экстрактов методом ДФПГ составила от 73,34 (Echinacea purpurea L.) до 92,56 (Calendula officinalis L.) \% (Sytar et al., 2018). В этом случае результаты оказались выше тех, что получили исследуя водные екстракты A. adhaerescens. Arituluk et al. (2016), изучая антиоксидантные параметры метанольных экстрактов 5 видов Tanacetum spp., определил антирадикальную активность исследуемых растворов (400 $\mu$ гмл) в пределах 77,61 - 84,41 \%, что было практически идентично сравнительно с исследуемыми нами растворами A. adhaerescens. 
Ресурсный потенциал вида в естественном ареале достаточно высок. Ареал его охватывает практически весь Приморский край, острова Сахалин и Кунашир, а также юг Хабаровского края. Растет этот вид преимущественно вдоль дорог, но в большом количестве. Локальные популяции имеют плотность 50 растений/м² и проективное покрытие до 98 \%. Практически это одновидовые заросли, что обеспечивает менее трудоемкий сбор сырья. Ресурсы возобновляются примерно через 5 лет, поскольку вид имеет большую семенную продуктивность (одно растение продуцирует 1,5 тысячи семян; почвенный семенной банк составляет 2,5 - 3,5 тыс. семян/м²) и способен разрастаться за счет вегетативного размножения, закладывая 1 - 2 зимующие почки (Vinogradova, 2013).

\section{Выводы}

Чужеродный A. adhaerescens, который успешно адаптировался к условиям московского климата и сформировал устойчивую инвазионную популяцию, может стать потенциальнымисточникомантиоксидантовдляулучшениясистемыантиоксидантной защитычеловека. Наиболеевысокойантиоксидантной активностью обладают молодые листочки, собранные в течение 1 - 2 недель после таяния снега, атакже соцветия в стадии начала цветения. Однако и вся надземная часть растений отличается повышенным содержанием веществ с антиоксидантной активностью: спиртовые экстракты 76-81 \%, а водные - 32-67 \%. Кроме того, растения из естественного и вторичного ареала не имеют существенных различий по содержанию веществ антиоксидантной активности, следовательно, при намеренной интродукции растений этот показатель не будет изменяться. Необходимо дальнейшее изучение фитохимических характеристик A. adhaerescens как в первичном, так и во вторичном ареалах для выявления образцов с высокой антиоксидантной активностью.

\section{Благодарности}

Исследование выполнено в рамках программы Министерства науки и образования № 19-119080590035- 9, с частичной поддержкой гранта РФФИ № 19-54-26010.

\section{Литература}

ARITULUK, Z.C., TATLI ÇANKAYA, I.I., GENÇTER ÖZKAN, A.M. 2016. Antioxidant activity, total phenolic and flavonoid contents of some Tanacetum L. (Asteraceae). In FABAD Journal of Pharmaceutical Sciences, vol. 41, p. 17-25.

AYRES, J.A. 1915. Flower of Adenocaulon bicolor. Botanical Gazett, p. 154-157.

BALUNAS, M., KINGHORN, A. 2005. Drug discovery from medicinal plants. In Life sciences, vol. 78(5), p. 431-441.

BESSADA, S.M.F., BARREIRA, J.C.M., OLIVEIRA, M.B.P.P. 2015. Asteraceae species with most prominent bioactivity and their potential applications: a review. In Industrial Crops and Products, vol. 76, p. 604-615. http://dx.doi.org/10.1016/j.indcrop.2015.07.073

BITTMANN, M. 1990a. Die Gattung Adenocaulon (Compositae): I. Morphologie. In Candollea, vol. 45, p. 389-420. 
Vinogradova, Y., Shelepova, O., Vergun, O., Ganina, A.

Agr.bio.div. Impr. Nut., Health Life Qual., 2020, 59-69

BITTMANN, M. 1990b. Die Gattung Adenocaulon (Compositae): II. Ökologie, Verbreitung und Systematik. Candollea, vol. 45, p. 493-518.

BREEDLOVE, D.E. 1986. Flora de Chiapas. Listados Florísticos de México, p. 1-246.

CRAGG, G., NEWMAN, D. 2005. Plants as a source of anti-cancer agents. In Journal of ethnopharmacology, vol. 100(1-2), p. 72-79.

DAUR, I. 2015. Chemical composition of selected Saudi medicinal plants. In Arabian Journal of Chemistry, vol. 8(3), p. 329-332. https://doi.org/10.1016/j.arabjc.2013.10.015

DEMIR, H., AÇIK, L., BALI, E. B., KOÇ, L. Y., KAYNAK, G. 2009. Antioxidant and antimicrobial activities of Solidago virgaurea extracts. In African Journal of Biotechnology, vol. 8(2), p. 274-279.

FUNK, V.A., HIND, D.J.N. 2016. Typification of species names in Adenocaulon and Eriachaenium (Compositae/Asteraceae, Subfamily Mutisioideae, Tribe Mutisieae, Subtribe Adenocaulinae). In PhytoKeys, vol. 69, p. 121.

GORIUNOVA, YU. 2009. Vliyanie ekologicheskih faktorov na soderzhanie $\mathrm{v}$ rasteniyah nekotoryh antioksidantov: avtoref. dis. kand. biol. Nauk. [The influence of environmental factors on the content in plants of some antioxidants: author. dis. biol. Sciences]. Kaliningrad. 22 p. [In Russian].

HAK, C. K., KANG, R. L. 2001. An Acetylene and a Monoterpene Glycoside from Adenocaulon himalaicum. In Planta Med, vol. 67(5), p. 482-484. https://doi.org/10.1055/s-2001-15806

HOOKER, W.J. 1829. Adenocaulon. In Botanical Miscellany, vol. 1(1), p. 19-20.

JUE, W., WANG, N., YAO, X., ISHII, R., KITANAKA, S. 2006. Inhibitory activity of Chinese herbal medicines toward histamine release from mast cells and nitric oxide production by macrophage-like cell line, RAW 264.7. In Journal of Natural Medicines, vol. 60(1), p. 73-77.

KEIL D. J. 1829. Adenocaulon Hooker. In Flora of North America. Page 77. 1: 19, plate 15.

KINJO, J., NAKANO, D., FUJIOKA, T. OKABE, H. 2016. Screening of promising chemotherapeutic candidates from plants extracts. In Journal of Natural Medicines, vol. 70(3), p. 335-336.

KOZUHAROVA, E., IONKOVA, I., RAIMONDO, F.M. 2019. Invasive alien spices: potential cheap resources of plant substances for medicinal use. In Flora Mediterranea, vol. 29, p. 13-25. https://doi. org/10.7320/FlMedit29.013

KRISHNAIAH, D., SARBATLY, R., NITHYANANDAM, R. 2011. A review of the antioxidant potential of medicinal plant species. In Food and Bioproducts Processing, vol. 89, p. 217-233.

KULESH, N., KRASOVSKAYA, N., MAKSIMOV, O. 1986. Fenol'nye soedineniya Aruncus dioicus i Adenocaulon adhaerescens [Phenolic compounds Aruncus dioicus and Adenocaulon adhaerescens]. In Chemistry of Natural Compounds, vol. 4, p. 507-508. [In Russian].

KWON, H.C., LEE, K.R. 2001. An Acetylene and a Monoterpene Glycoside from Adenocaulon himalaicum. In Planta Med, vol. 65(5), p. 482-484.

LEE, K. 2010. Discovery and development of natural product-derived chemotherapeutic agents based on a medicinal chemistry approach. In Journal of natural products, vol. 73(3), p. 500-516.

MARINOVA, G., BATCHVAROV, V. 2011. Evaluation of the methods for determination of the free radical scavenging activity by DPPH. In Bulgarian Journal of Agricultural Science, vol. 17(1), p. 11-24.

MARTICORENA, C., QUEZADA, M. 1985. Catálogo de la Flora Vascular de Chile. In Botánica, vol. 42, p. $1-157$.

MAXIMOWICZ, C. 1859. Adenocaulon. In Mémoires Presentes a l'Académie Impériale des Sciences de St.Pétersbourg par Divers Savans et lus dans ses Assemblées, vol. 9, p. 152.

MAYOROV, S., VINOGRADOVA, YU., BOCHKIN, V. 2013. Illyustrirovannyj katalog rastenij, dichayushchih $\mathrm{v}$ botanicheskih sadah Moskvy [Illustrated catalog of plants escaping from collections within the botanical gardens of Moscow]. Moskva: Fiton XXI. 160 p. [In Russian].

NASH, D. L., NASH, D.L., WILLIAMS, L.O. 1976. Tribe IV, Inuleae. In Flora of Guatemala, Part XII, vol. 24(12), p. 164-181, 496-502. 
OIKAWA, S., SUNO, K., OSADA, N. 2017. Inconsistent intraspecific pattern in leaf life span along nitrogensupply gradient. In American Journal of Botany, vol. 104(2), p. 342-346.

PAPPAN, A., THOMAS, B. 2017. Contribution of invasive plants in herbal medicinal practices. In International Journal of Herbal Medicine, vol. 5(2), p. 73-77.

SHELEPOVA, O., VINOGRADOVA, YU., GRYGORIEVA, O., VERGUN, O., BRINDZA, J. 2019. Invasive Solidago canadensis as a resource of valuable biological compounds. In Potravinarstvo Slovak Journal of Food Sciences, vol. 13(1), p. 280-286. https://doi.org/10.5219/1125

SYTAR, O., HEMMERICH, I., ZIVCAK, M., RAUH, C., BRESTIC, M. 2018. Comparative analysis of bioactive phenolic compounds composition from 26 medicinal plants. In Saudi Journal of Biological Sciences, vol. 25, p. 631-641. https://doi.org/10.1016/j.sjbs.2016.01.036

VINOGRADOVA, YU. 2010. The biology of Adenocaulon adhaerescens in initial invasive population. In 6 th NEOBIOTA Conference Biological invasions in a changing world from science to management. Copenhagen, p. 184. ISBN: 978-87-993976-0-0

VINOGRADOVA, YU. 2013. Adenocaulon adhaerescens Maxim. Biologiya i ekologiya rasteniy rossiyskogo Dalnego Vostoka [Biology and ecology of plants in Russian Far East]. Ussuriysk : Far East State University, p. 99-106 [In Russian].

VINOGRADOVA, YU., GANINA, A., VERGUN, O. 2019a. Possibility of using alien Adenocaulon adhaerescens Maxim. (Asteraceae) as the medicine plant. In 4th International scientific Conference Agrobiodiversity for improve the Nutrition, Health and Quality of Human and Bees Life. Nitra. p. 149. ISBN 978-80-552-2037-6.

VINOGRADOVA, YU., VERGUN, O., GRYGORIEVA, O., BRINDZA, J. 2019b. Antioxidant activity of alien Galinsoga species In 4th International scientific Conference Agrobiodiversity for improve the Nutrition, Health and Quality of Human and Bees Life. Nitra, p. 150. ISBN 978-80-552-2037-6.

WANG, X., ZHANG, Q. JIA, Z. 2001. A new tricyclic- $\alpha, \beta$-unsaturate ketone and a new $\delta$-hexano lactone glycoside from Adenocaulon himalaicum. In Natural Product Research, vol. 21(2), p. 61-166.

YOUSHENG, C., HIND, N. 1829. Adenocaulon Hooker. In Flora of China, vol. 20-21, p. 10. 